Original Research

\title{
Spatial-Temporal Characteristics and Factors of Agricultural Carbon Emissions in the Belt and Road Region of China
}

\author{
Ying Zhou*, Tong Wang, Rongcun Peng, Huimin Hu \\ College of Architecture and Urban Rural Planning, Sichuan Agricultural University, Sichuan 611830, China
}

Received: 20 May 2020

Accepted: 9 September 2020

\begin{abstract}
The implementation of the "Belt and Road" strategy not only promotes the coordinated development of China's regional economy but also generates a large amount of greenhouse gas emissions. The research and policy recommendations on agricultural carbon emissions are of great significance for China toward engendering sustainable agricultural development and appreciably contributing to the alleviation of global climate change. In this paper, agricultural carbon emissions in the Belt and Road region of China from 2003-2018 are calculated, and its spatial-temporal characteristics are analyzed. Then, we modified the logarithmic mean Divisia index model from the original four factors to six to analyze the drivers of agricultural carbon emissions. The research results obtained are as follows: (1) Total carbon emission reached a peak of 26.6326 million tons in 2016, representing a $54.53 \%$ increase from the 17.2342 million tons in 2003. Moreover, it indicated a downward trend in 2017 and dropped by approximately $4 \%$ to 25.5685 million tons in 2018. (2) Spatially, agricultural carbon emission varies greatly, with the highest value recorded in Heilongjiang and the lowest in Tibet, thereby exhibiting the characteristics of "northwest>northeast>southwest>southeast." (3) Overall, the economic factor was the most important driving factor, whereas the subsidy factor was the strongest inhibiting factor for the growth of agricultural carbon emissions. Notably, the foreign trade factor had both promoting and inhibiting effects on it.
\end{abstract}

Keywords: agricultural production activities, Belt and Road, $\mathrm{CO}_{2}$ emissions, LMDI model, spatial-temporal

\section{Introduction}

In recent times, the world has been undergoing profound and complex changes, and the aspiration

*e-mail: zhouying3333@163.com for peace, development, and cooperation has become a prevalently contemporary issue. Notably, countries around the world have been accelerating the readjustment of their development strategies, promoting innovation, and improving their economic structures. To converge global economic ties, enhance cooperation, and broaden development channels, the Chinese government expounded the strategic initiative 
of building the "Silk Road Economic Belt" and the " $21^{\text {st }}$ Century Maritime Silk Road" in 2013, subsequently referred to as the "Belt and Road" initiative, which would not only ameliorate the external environment for China's development but also significantly contribute to the optimization and improved coordination of regional development patterns. Accelerating the Belt and Road construction is conducive toward promoting the economic prosperity and regional economic cooperation for countries along the Belt and Road region, as well as to enhance exchanges and mutual learning among different civilizations. This entails a great undertaking that will be beneficial to people worldwide.

However, implementing the Belt and Road strategy will inevitably lead to an increase in carbon emissions while promoting regional economic growth. Greenhouse gas (GHG) emissions are the main cause of global warming and have become one of the biggest threats to human sustainable development [1]. A large number of studies have proven the significant effects of air pollution, such as atmospheric heavy metal pollution based on urban traffic, on human health $[2,3]$. Notably, China has overtaken the US as the world's biggest emitter of carbon dioxide $[4,5]$. As a large agricultural country, China's agricultural carbon emissions account for approximately $17 \%$ of the total national emissions [6], and the need to reduce agricultural carbon emissions and develop low-carbon agriculture is highly imperative. Consequently, the Chinese government has formulated the $13^{\text {th }}$ five-year plan for controlling GHG emissions, which aims to effectively control the total amount of carbon emissions and implement the carbon emission reduction commitment [7].

Regional difference is another inevitable problem in the process of a country's economic and social development. Agricultural production activities are conducted under specific geographical environment, soil, and climate conditions, which essentially connote regional characteristics. Therefore, there are large regional differences in carbon emissions from agricultural production activities in different regions, which is consequent to the joint action of natural and social factors. China has a vast territory, and the amount and intensity of agricultural carbon emissions in the spatial distribution vary greatly among provinces, which will increase over time [8]. The appraisal of temporal and spatial characteristics is based on the descriptive analyses of time trends and interprovincial differences. Therefore, studying the agricultural carbon emissions in China's Belt and Road region will help in the formulation of unique emission reduction policies for different regions, which is greatly significant to the promotion of the Belt and Road construction, realization of carbon emission reduction targets, and sustainable development of Chinese agriculture.

Presently, research on carbon emissions mainly focuses on their evaluation, influencing factors, as well as interrelationship with specified factors, and so on.
Carbon emission accounting directly affects the formulation of carbon emission policies. Yadav and Wang [9] modified the process-based DeNitrificationDeComposition model and predicted that as fertilizer use and irrigation decrease, so will $\mathrm{CO}_{2}$ emissions. To determine the change in air quality, Cetin and Sevik [10] measured and evaluated particulate matter and $\mathrm{CO}_{2}$ amounts in seven regions with different properties in the Kastamonu city. Adewale et al. [11] proposed three principles for calculating agricultural carbon footprints by comparing published studies on them. Lu et al. [12] calculated the total carbon emissions from agricultural land use in 31 provinces in China from 2000-2015, and found that the central provinces had far higher emission rates than others. Chu et al. [13] discovered that approximately three-quarters of the agro-ecosystem carbon footprint originated from energy consumption in Hebei province. Cetin et al. [14] concluded that the amount of $\mathrm{CO}_{2}$ in caves increased progressively deeper into the cave; from $1200 \mathrm{ppm}$ at $50 \mathrm{~m}$ inside the cave entrance to $2500 \mathrm{ppm}$ at $150 \mathrm{~m}$. Chuai and Feng [15] detected the carbon emissions caused by energy consumption in Nanjing with a high resolution of $300 \mathrm{~m}$; the results showed that $90 \%$ of the carbon emissions in Nanjing emanated from industries, and land use was the most critical factor to determine carbon emission.

The research on the influencing factors of carbon emission is conducive to its targeted control. Sumabat et al. [16] used the logarithmic mean Divisia index (LMDI) model to quantify the driving forces of changes in $\mathrm{CO}_{2}$ emissions in the Philippines from 1991-2014. The results confirmed the negative impact of economic growth and rising living standards to $\mathrm{CO}_{2}$ emissions. Cetin [17] found that the amount of $\mathrm{CO}_{2}$ in exam halls was influenced by weather, season, location of the exam building, and number of candidates, as well as that decreasing the number of students per exam hall may have a positive effect on $\mathrm{CO}_{2}$ levels. Akram et al. [18] concluded that energy mix effects were the greatest contributors to the increase in $\mathrm{CO}_{2}$ emissions in Pakistan. $\mathrm{Xu}$ and Lin [19] found that energy intensity was positively correlated with emissions, and showed a downward trend from the eastern region to the central and western regions. Cui et al. [20] indicated there was an inverted U-shaped environmental Kuznets curve between economic growth and carbon emissions in the Hebei province. Xiong et al. [21] found that the role of labor force in increasing agricultural carbon emissions was becoming progressively evident. Taking the Henan province for example, Su et al. [22] discovered that agricultural labor productivity could greatly promote increasing carbon emissions. Through the comparison of development scenarios, Zhang et al. [23] proposed the optimal low-carbon development model suitable for the Henan province.

The study of the relationship between carbon emissions and a specified factor is a more detailed analysis of the parameters that affect carbon emissions. 
Cetin and Sevik [24] attempted to determine the effects of indoor plants on $\mathrm{CO}_{2}$ concentration in an indoor environment under certain light conditions. They found that all plants reduced $\mathrm{CO}_{2}$ concentration to a certain extent during the day and were affected by the light they received in the environment. Ismael et al. [25] examined the interaction between agricultural technology factors and carbon emission in Jordan. The results provided evidence for the unidirectional causality running from machinery, subsidies, and other transfers, as well as rural access to an improved water source and fertilizers to carbon emissions, while also revealing a bidirectional causality relationship between real income and carbon emissions. Engo [26] found that Cameroon showed a weak decoupling between economic growth and $\mathrm{CO}_{2}$ emissions from 1990-2015. By appraising how GHG emissions have changed with respect to agricultural production (elasticity) from 1990-2015, Saravia-Matus et al. [27] revealed that very few countries in Latin America and the Caribbean were in a process of effectively decoupling agricultural and agriculture, forestry, and other land use emissions from agricultural production. Xiong et al. [28] analyzed the decoupling relationship between agricultural carbon emissions and agricultural economic growth in Hotan from 1999-2013 and found that they were mainly in a state of negative decoupling expansion.

Summarily, many researchers have extensively investigated $\mathrm{CO}_{2}$ emissions from agriculture; however, there have merely been a few studies on the agricultural carbon emission of China's provinces along the Belt and Road region [29]. The research on China's agricultural carbon emissions is mainly analyzed from the perspective of a country's comprehensive situation or a single province. However, under the Belt and Road strategy, only a few studies have compared the agricultural carbon emissions of provinces in the Belt and Road region of China to establish their commonalities and differences. The Belt and Road plan will affect the global carbon emission trajectory. Therefore, as the advocate, it is very important for China to accurately grasp the driving mechanism of agricultural carbon emissions in the Belt and Road region, as well as enshrine low-carbon development.

This paper calculates agricultural carbon emissions in the Belt and Road region of China from 2003-2018, and analyzes its spatial-temporal characteristics. Thereafter, we modify the LMDI model to study the driving factors of agricultural carbon emissions. Finally, we present the final conclusion and policy recommendations to provide a reference for the government toward formulating scientific and feasible carbon emission mitigation policies in the Belt and Road region of China, as well as to make a useful contribution to alleviate global climate change.

\section{Material and Methods}

\section{Study Area}

In China, the Belt and Road region (Fig. 1) includes six provinces in the northwest, including Xinjiang, Shaanxi, Gansu, Ningxia, Qinghai, and Inner Mongolia;
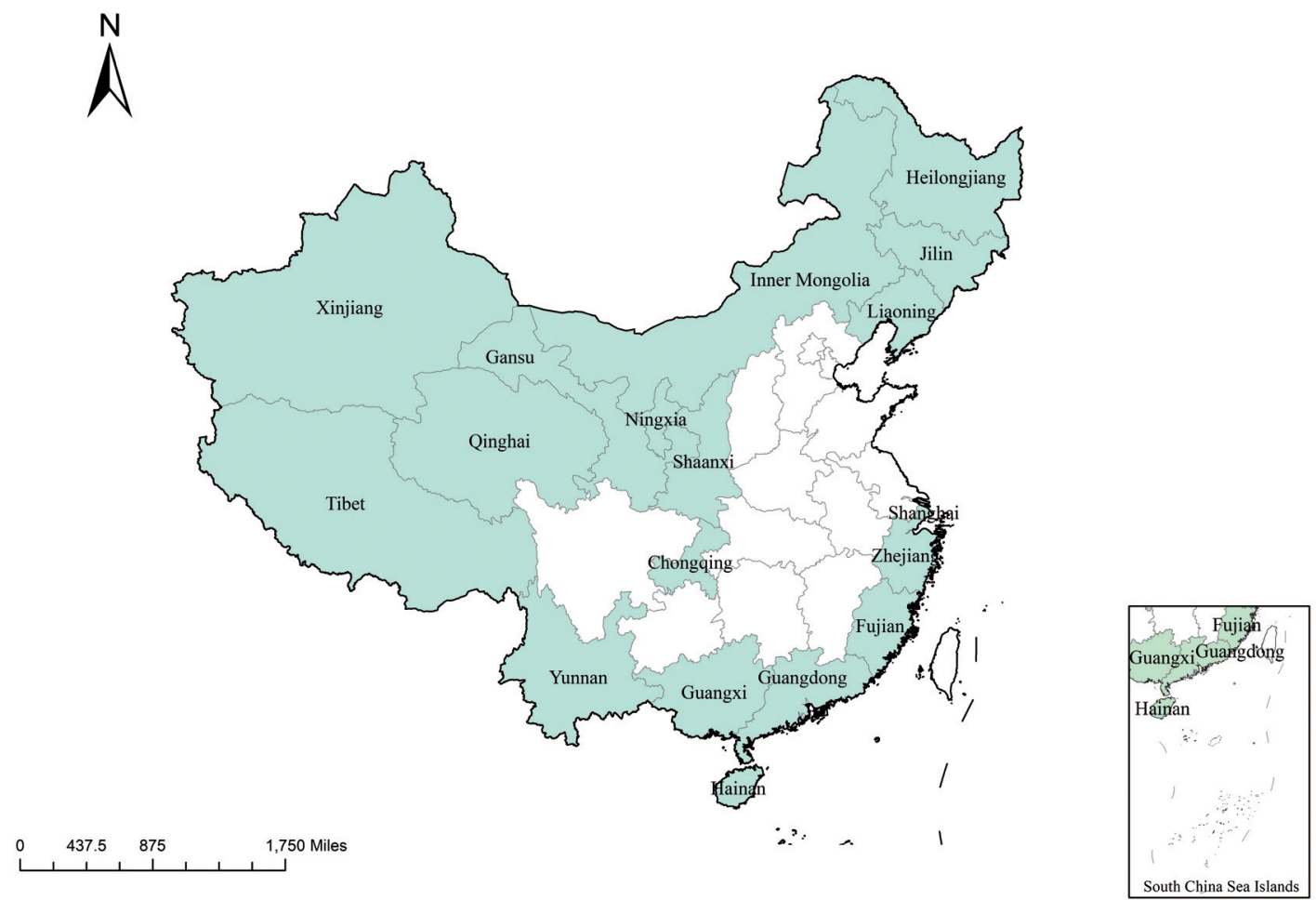

Fig. 1. Study Area. 
three provinces in the northeast, including Heilongjiang, Jilin, and Liaoning; three provinces in the southwest, including Guangxi, Yunnan, and Tibet; five provinces in the southeast, including Shanghai, Fujian, Guangdong, Zhejiang, and Hainan; and Chongqing in the interior. According to the China Statistical Yearbook (2019), in 2018, the gross agricultural output value in the Belt and Road region was 5117.09 billion yuan, accounting for $45.05 \%$ of the nation's total. The implementation of the Belt and Road strategy rejuvenates regional agriculture and promotes the rapid development of the agricultural economy. Meanwhile, agricultural carbon emissions have continued to increase for various reasons, including unreasonable industrial structure, low technological level, and inadequate utilization of agricultural materials.

\section{Calculation Method of Agricultural Carbon Emissions}

Notably, agricultural land use is the main source of agricultural carbon emissions, and agricultural production activities have a greater impact on the carbon cycle. In this paper, the total agricultural carbon emissions in the Belt and Road region are mainly considered, including the following three main parts: (1) carbon emissions from the use of chemicals, such as pesticides, fertilizers, and agricultural plastic films, in farming activities; (2) carbon emissions from energy consumption, such as the use of fossil fuels by agricultural machinery and the utilization of electricity in agricultural irrigation; and (3) loss of organic carbon through tillage.

Here, six aspects, i.e., pesticides (t), chemical fertilizers ( $\mathrm{t}$ ), agricultural plastic films ( $\mathrm{t}$ ), agricultural diesel oil (t), agriculture ploughing, and agriculture irrigation, are selected from 18 provinces and cities as sources of agricultural carbon, including total sown area of crops $\left(\mathrm{hm}^{2}\right)$ as the data of agriculture ploughing and effective irrigated area $\left(\mathrm{hm}^{2}\right)$ as the agricultural irrigation data based on the estimated area along the regional agricultural carbon emissions in 18 provinces and cities.

Based on the carbon emission measurement method provided by the Intergovernmental Panel on Climate Change (2006), the total carbon emissions from six agricultural carbon sources can be calculated by Equation (1):

$$
C=\sum A_{i} B_{i}
$$

...where, $C$ indicates the total carbon emissions from six agricultural carbon sources, $A_{\mathrm{i}}$ represents the consumption (amount) of the $i$-th carbon source, and $B_{\mathrm{i}}$ is the coefficient of the $i$-th carbon source. The carbon sources and coefficients are shown in Table 1.

\section{Decomposition of Carbon Emissions Factors}

In this paper, the LMDI model is used to decompose the influencing factors of agricultural carbon emissions in the Belt and Road region of China. The LMDI model has good decomposition and aggregation consistency, and the complete decomposition ensures that there are no unexplainable residuals in the obtained decomposition results, thereby overcoming the shortcomings of the existence or improper residual decomposition inherent in other methods [34-36].

According to the LMDI analysis framework, combined with the actual situation of agricultural carbon emissions, the total carbon emissions can be expressed as follows:

$$
C=\frac{C}{P G D P} \times \frac{P G D P}{A G D P} \times \frac{A G D P}{A L} \times A L
$$

...where, $C, P G D P, A G D P$, and $A L$ separately represent the total agricultural carbon emissions, planting industry gross output value, agricultural gross output value, and employment labor of the agricultural industry. Considering the Belt and Road policy, national financial subsidies to agriculture and foreign trade are also important considerations. The proposal of the Belt and Road initiative makes the foreign trade market of agricultural products more extensive, which may indirectly lead to the deterioration of agricultural ecological environment. However, through the rational use of financial support funds and the introduction of energy-saving agricultural machinery, the green development of agriculture can be promoted.

Table 1. Carbon emission coefficients of major carbon sources.

\begin{tabular}{|c|c|c|}
\hline Carbon Sources & Emission Coefficient & Reference \\
\hline Pesticide & $0.0049341 \mathrm{~kg} / \mathrm{t}$ & Zhi and Gao [30] \\
\hline Chemical Fertilizer & $895.6 \mathrm{~kg} / \mathrm{t}$ & Tian [31] \\
\hline Agricultural Plastic Films & $0.00518 \mathrm{~kg} / \mathrm{t}$ & Tian [31] \\
\hline Agricultural Diesel Oil & $0.0005927 \mathrm{~kg} / \mathrm{t}$ & Wu [32] \\
\hline Agriculture Ploughing & $312.6 \mathrm{~kg} / \mathrm{hm}^{2}$ & West [33] \\
\hline Agricultural Irrigation & $266.48 \mathrm{~kg} / \mathrm{hm}^{2}$ & \\
\hline
\end{tabular}


Consequently, we rewrite Equation (2), as represented in Equation (3):

$$
\begin{gathered}
C=\frac{C}{P G D P} \times \frac{P G D P}{A G D P} \times \frac{A G D P}{A L} \times \frac{A L}{A F E} \times \frac{A F E}{F D I} \times F D I= \\
E I \times C I \times S I \times K \times Y \times F D I
\end{gathered}
$$

...where, $A F E$ and FDI represent the agricultural financial expenditure and foreign direct investment in actual agricultural use, respectively. Moreover, EI, CI, $S I, K, Y$, and FDI represent the efficiency, structure, economic, subsidy, policy, and foreign trade factors, respectively.

In Equation (3), the total agricultural carbon emissions of base period and $T$ period are set as $C^{0}$ and $C^{t}$, and the subscript "tot" represents the total change. By applying additive decomposition, the expression of the contributive value of each decomposition factor is given as follows:

$$
\begin{aligned}
& \Delta E I=\sum \frac{C^{t}-C^{0}}{\ln C^{t}-\ln C^{0}} \ln \frac{E I^{t}}{E I^{0}} \\
& \Delta C I=\sum \frac{C^{t}-C^{0}}{\ln C^{t}-\ln C^{0}} \ln \frac{C I^{t}}{C I^{0}} \\
& \Delta S I=\sum \frac{C^{t}-C^{0}}{\ln C^{t}-\ln C^{0}} \ln \frac{S I^{t}}{S I^{0}} \\
& \Delta K=\sum \frac{C^{t}-C^{0}}{\ln C^{t}-\ln C^{0}} \ln \frac{K^{t}}{K^{0}} \\
& \Delta Y=\sum \frac{C^{t}-C^{0}}{\ln C^{t}-\ln C^{0}} \ln \frac{Y^{t}}{Y^{0}} \\
& \Delta F D I=\sum \frac{C^{t}-C^{0}}{\ln C^{t}-\ln C^{0}} \ln \frac{F D I^{t}}{F D I^{0}}
\end{aligned}
$$

The total effect is:

$$
\Delta C_{\text {tot }}=C^{t}-C^{0}=\Delta E I+\Delta C I+\Delta S I+\Delta K+\Delta Y+\Delta F D I
$$

\section{Data Sources}

The data of the pesticides, fertilizers, agricultural film, agricultural diesel, agricultural till-over, and agricultural irrigation are all from the China Rural Statistical Yearbook (2004-2019). The data required to analyze the driving factors of agricultural carbon emissions are shown in Table 2.

\section{Results and Discussion}

\section{Temporal Characteristics and Spatial Contrast of} Agricultural Carbon Emissions

Using Equation (1), we calculate the agricultural carbon emissions of the Belt and Road region of China from 2003-2018; the overall trend is shown in Fig. 2.

The results show that the total agricultural carbon emissions exhibited an upward trend from 2003-2016, and reached the peak in 2016. The total carbon emission in 2016 was 26.6326 million tons, indicating

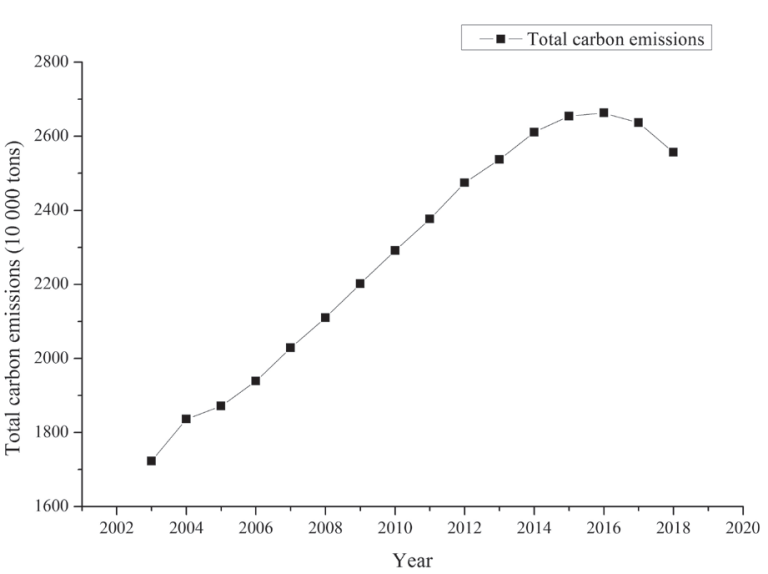

Fig. 2. Total agricultural carbon emissions in the Belt and Road region from 2003-2018.

Table 2. Data needed to analyze the driving factors of agricultural carbon emissions.

\begin{tabular}{|c|c|}
\hline Data required by the LMDI model & Data Source \\
\hline Total agricultural carbon emissions & Calculated from the above Equation (1) \\
\hline Total output value of planting industry & China Rural Statistical Yearbook (2004-2018) \\
\hline Total output value of agriculture, forestry, animal husbandry and fishery & China Rural Statistical Yearbook (2004-2018) \\
\hline Agricultural financial expenditure & China Statistical Yearbook (2004-2018) \\
\hline Agricultural labor force & Statistical Yearbooks of 18 provinces and cities(2004-2018) \\
\hline Foreign direct investment in agriculture & Statistical Yearbooks of 18 provinces and cities(2004-2018) \\
\hline
\end{tabular}




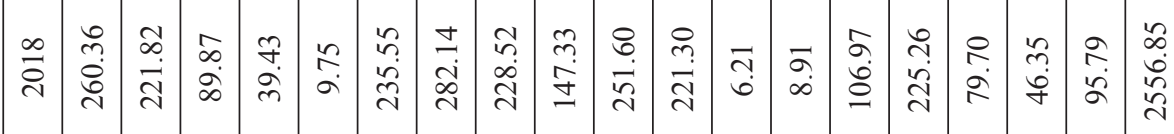

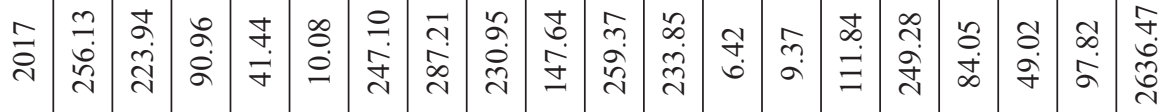

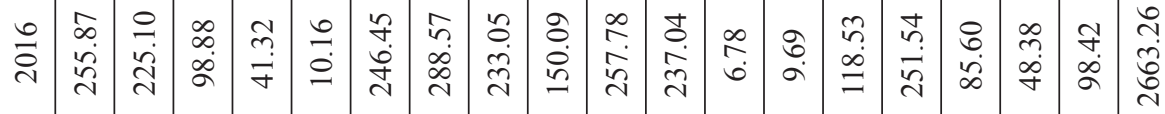

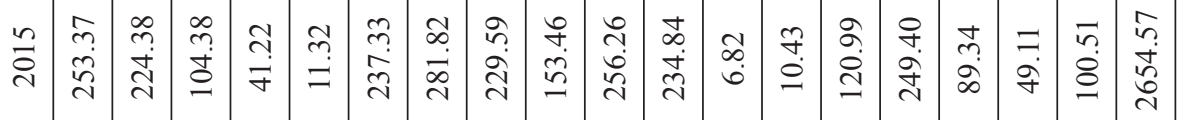

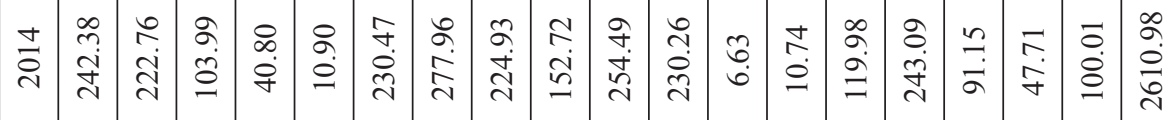

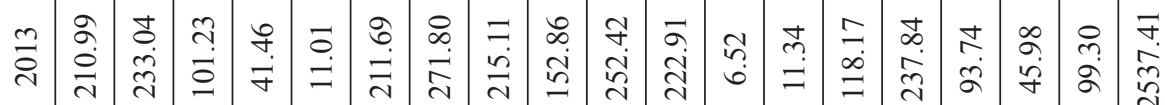
更

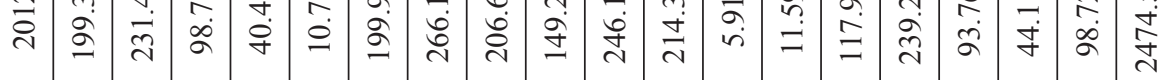

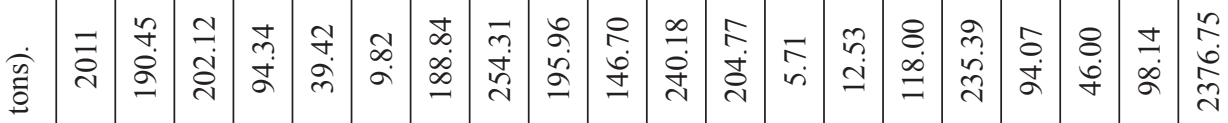
8

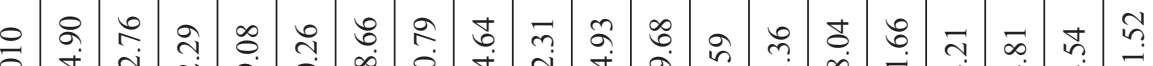
$\stackrel{\infty}{\stackrel{\infty}{\circ}}$ \&े

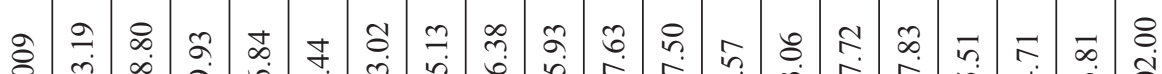
.5

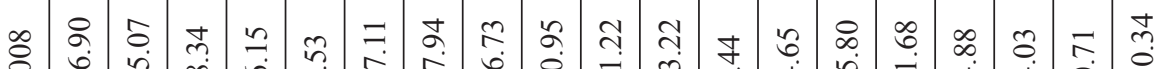

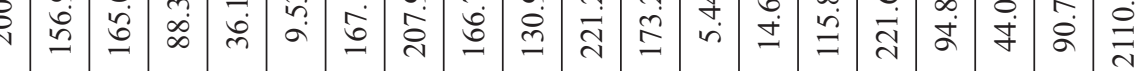

ऽ J

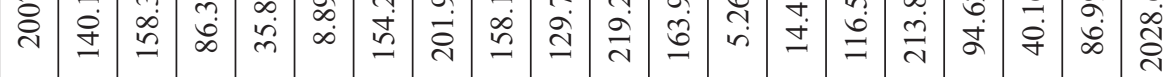

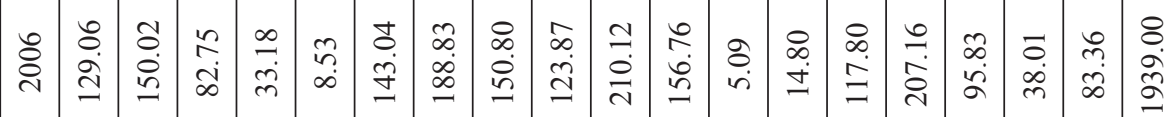

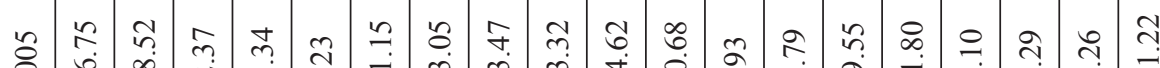

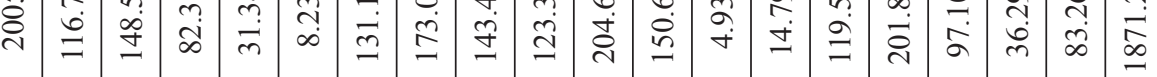

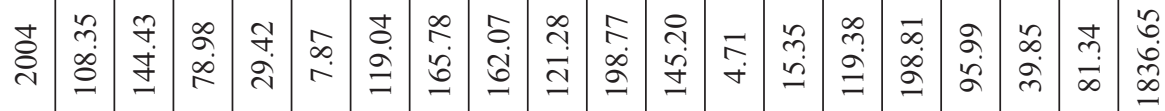

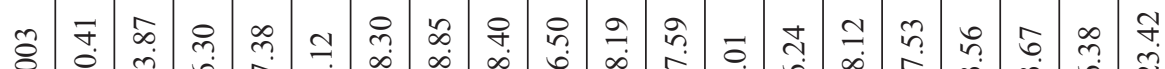

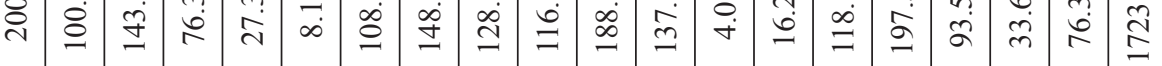

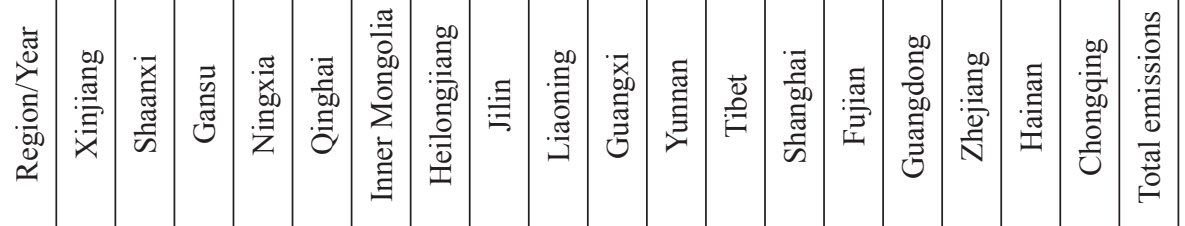


a $54.53 \%$ increment over the 17.2342 million tons in 2003, with an average annual increase of $3.40 \%$. It revealed a downward trend in 2017 and dropped by approximately $4 \%$ to 25.5685 million tons in 2018 . In addition, agricultural carbon emissions grew at the fastest rate from 2003-2004 and the slowest from 2015-2016. After the "Belt and Road" initiative was proposed, the growth rate of agricultural carbon emissions showed a gradual decline from 2013-2016. The inflection point of total agricultural carbon emissions in 2016 is largely due to the Chinese government's increased emphasis on the protection of the ecological environment and a series of policies to develop a low-carbon economy. Besides, fertilizer is the most important source of carbon emissions, but since 2016, its use has decreased significantly.

Table 3 shows the calculation results of agricultural carbon emissions of each province in the Belt and Road region from 2003-2018 in detail.

From the provincial level (Table 3), agricultural carbon emission spatial differences are also evident. The fastest growth rate of agricultural carbon emissions is in Xinjiang, with an average annual growth rate of $6.56 \%$, followed by Inner Mongolia, Heilongjiang, and Jilin, with average annual growth rates of 5.32, 4.36, and 3.92\%, respectively. Apparently, most of the provinces with fast carbon emission growth rates are in North China, but their growth rate has the tendency to decline. In Tibet, Qinghai, and Shanghai, agricultural carbon emissions fluctuate marginally, especially in Shanghai, which even show a relatively evident downward trend. On the one hand, because Shanghai is located in the economically developed area in East China, its agricultural production area is limited. On the other hand, it also attaches more importance to the protection of the ecological environment.

In the ranking of agricultural carbon emission in the Belt and Road region from 2003-2018, the top
Table 4. Belt and Road region division.

\begin{tabular}{|c|c|}
\hline Region & Contains provinces \\
\hline Northwest & $\begin{array}{c}\text { Xinjiang, Shaanxi, Gansu, Ningxia, Qinghai, } \\
\text { Inner Mongolia }\end{array}$ \\
\hline Northeast & Heilongjiang, Jilin, Liaoning \\
\hline Southwest & Guangxi, Yunnan, Tibet, Chongqing \\
\hline Southeast & $\begin{array}{c}\text { Shanghai, Fujian, Guangdong, Zhejiang, } \\
\text { Hainan }\end{array}$ \\
\hline
\end{tabular}

three are Heilongjiang, Guangxi, and Guangdong, with annual averages of 2.3515, 2.3269, and 2.2696 million tons, respectively, accounting for $30.45 \%$ of the total agricultural carbon emissions. Heilongjiang is a major planting province and its fertile land is an important national food production base. Nonetheless, regardless of the high economic benefits, the emission from agricultural land use has become one of the most worrisome environmental issues in Heilongjiang. The high agricultural economic growth in Heilongjiang, Guangxi, and Guangdong has been at the cost of high input and soaring carbon emissions. Compared with other provinces in the Belt and Road region, fertilizer input has always been a front burner issue, and the high carbon emission from fertilizer significantly elevates the ranking of the total agricultural carbon emissions of the three provinces.

The bottom three provinces, in connection to total agricultural carbon emissions, were Tibet, Qinghai, and Shanghai, with annual averages of 57300,96 700, and 125200 tons, respectively, accounting for only $1.22 \%$ of the total agricultural carbon emissions. This is predominantly because the main source of agricultural carbon emissions in Tibet and Qinghai is animal husbandry, and the amount of chemical fertilizer employed in the process of agricultural land use is less.

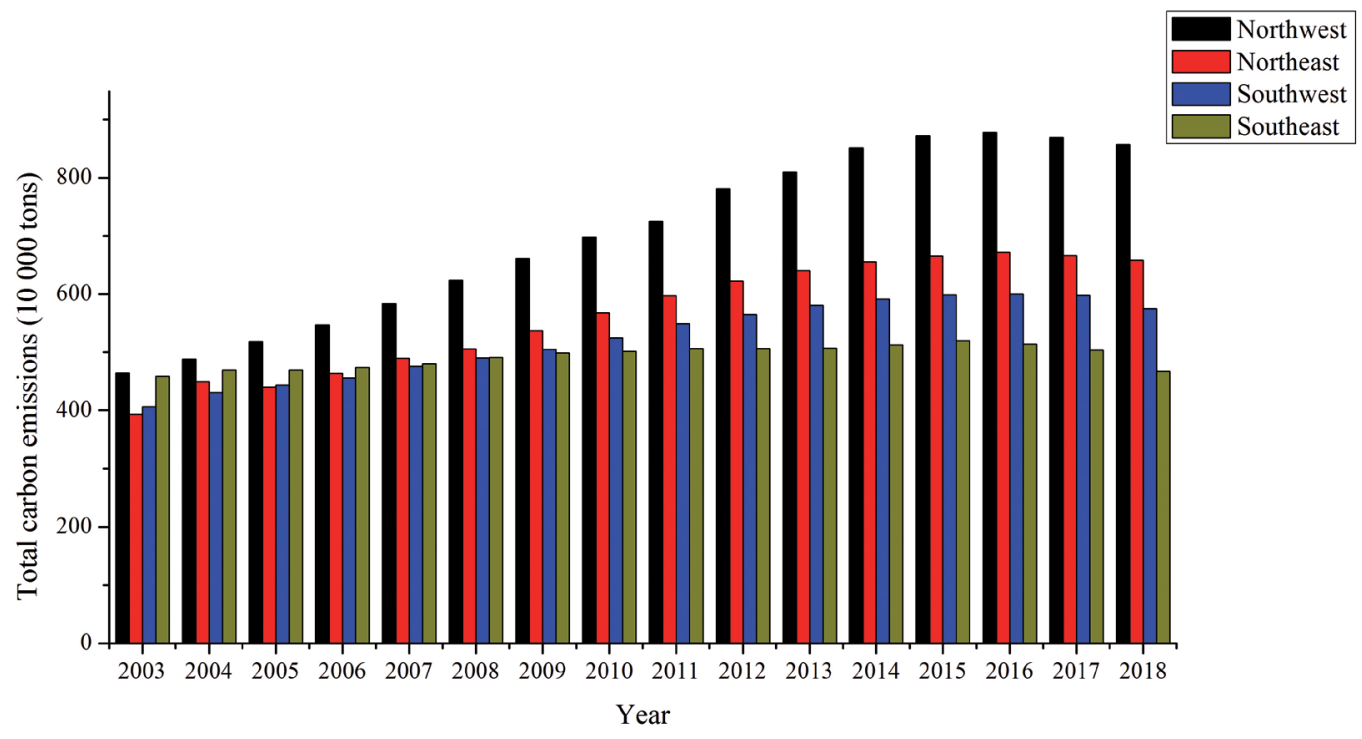

Fig. 3. Changes in agricultural carbon emissions in different regions from 2003-2018. 
According to the above analysis, the total annual carbon emission of the Heilongjiang province (the first) is 41.07 times that of Tibet (the last), thereby indicating that the total agricultural carbon emissions of different provinces and cities vary greatly.

Based on the geographical location of 18 provinces and cities, we divided the Belt and Road region of China into four different zones: northwest, northeast, southwest, and southeast regions (see Table 4).

As shown in Table 4 and Fig. 3, from 2003-2018, the total agricultural carbon emissions in the northwest, northeast, southwest, and southeast regions manifested a trend of continuous growth in the early period, although at a decelerating rate, and the declining trend appeared in the later period. Comparing the total agricultural carbon emissions of the four regions, the northwest region has always been in the leading position, with an average annual agricultural carbon emission of 7.0163 million tons, accounting for approximately $30.74 \%$ of the Belt and Road region, followed by the northeast region, and least in the southeast region, accounting for only $21.58 \%$. In terms of growth rate, agricultural carbon emissions in the northwest region grew the fastest, with an average annual growth rate of $4.17 \%$, while the southeast had the lowest growth rate of $0.12 \%$.
This distribution pattern is largely due to the following reasons:

1. Along with the advancement of western development, the economy of the western region has been growing rapidly. Furthermore, there are large agricultural production areas in the western region, and the increasing inputs of fertilizers, pesticides, and other materials lead to the continuous progression of total carbon emissions.

2. The three northeastern provinces (Heilongjiang\& Jilin\& Liaoning) have the largest black land area in China, and carbon emission from agricultural materials and land use is the main source. However, there are some problems in the development of agricultural production in the northeast region, such as weak awareness of resources and environment, unreasonable industrial structure, and farmers' abuse of chemical fertilizer and pesticide utilization, which causes great damage to the ecological environment.

3. The southeast region is located in the coastal zone, with less arable land and developed economy. The main source of carbon emissions is energy consumption. It has advantages in agricultural technology level, industrial structure, and farmers' individual conditions; moreover, its energy conservation and emission

Table 5. Cumulative effect from 2003-2017 of each driving factor on 18 provinces and cities.

\begin{tabular}{|c|c|c|c|c|c|c|c|}
\hline Region/Factor & $\Delta E I$ & $\Delta C I$ & $\Delta S I$ & $\Delta K$ & $\Delta Y$ & $\Delta F D I$ & Total Effect \\
\hline Xinjiang & -111.0892 & -5.3464 & 217.6073 & -466.0311 & 1700.4585 & -1218.7914 & 116.8078 \\
\hline Shaanxi & -250.6746 & 17.3307 & 354.9837 & -544.3969 & 335.6499 & 167.1757 & 80.0686 \\
\hline Gansu & -104.2724 & -0.7011 & 124.2301 & -289.6161 & 732.2806 & -548.1819 & -86.2609 \\
\hline Ningxia & -47.7566 & 3.6577 & 57.0685 & -113.8919 & -21.3584 & 25.4837 & -96.7971 \\
\hline Qinghai & -14.2825 & 1.4063 & 17.6713 & -35.0210 & - & - & -30.2258 \\
\hline Inner Mongolia & -99.0033 & 6.7928 & 218.3963 & -515.0436 & -99.1732 & 626.8380 & 138.8070 \\
\hline Heilongjiang & -296.1894 & 30.2756 & 429.7367 & -676.5503 & -331.0641 & 982.1544 & 138.3628 \\
\hline Jilin & 0.2430 & -42.7096 & 183.2813 & -603.9593 & - & - & -463.1446 \\
\hline Liaoning & -126.8538 & 7.4133 & 147.7864 & -307.7697 & 634.5058 & -323.9395 & 31.1426 \\
\hline Guangxi & -295.4408 & 27.2476 & 362.4813 & -714.6158 & 1361.3520 & -669.8449 & 71.1793 \\
\hline Yunnan & -187.2175 & -9.0102 & 317.9597 & -489.0621 & 375.8319 & 87.7622 & 96.2640 \\
\hline Tibet & -3.9721 & -0.0351 & 5.5297 & -18.8137 & - & - & -17.2912 \\
\hline Shanghai & -13.1470 & 3.7235 & 10.3814 & -46.0358 & 44.4783 & -6.2667 & -6.8662 \\
\hline Fujian & -145.9520 & -5.6323 & 168.9906 & -353.8833 & - & - & -336.4770 \\
\hline Guangdong & -219.8056 & 17.3613 & 293.6412 & -504.5533 & 701.9750 & -236.8748 & 51.7438 \\
\hline Zhejiang & -107.3866 & 7.4373 & 147.6069 & -289.0506 & 66.4094 & 114.5417 & -60.4420 \\
\hline Hainan & -51.1695 & 7.4978 & 54.2694 & -136.0017 & 229.0298 & -206.5416 & -102.9158 \\
\hline Chongqing & -112.9335 & 9.8379 & 166.3143 & -311.4910 & 345.4069 & -75.6928 & 21.4418 \\
\hline
\end{tabular}

Note: According to the Statistical Yearbooks (2004-2018) of Qinghai, Jilin, Tibet, and Fujian, the amount of FDI actually utilized in agriculture, forestry, animal husbandry, and fishery from 2003-2017 is unavailable, so the data on policy factor and foreign trade factor from 2004-2017 are invalid (-). 
reduction, as well as environmental governance capacity are also higher than that of the western region.

Ultimately, the ranking of the total agricultural carbon emissions in the Belt and Road region of China is northwest $>$ northeast $>$ southwest $>$ southeast, and this regional gap has no tendency to decrease.

\section{Driving Mechanism Decomposition Results}

Based on the extended LMDI model, using Equations (3-9), we only analyzed the driving factors and annual impacts of agricultural carbon emission changes from 2003-2017 since the Statistical Yearbooks of some provinces and cities in 2019 had not been released. The results are shown in Table 5 and Table 6.

Generally, the economic factor promotes agricultural carbon emissions in all provinces and cities in the Belt and Road region of China, while the subsidy factor completely inhibits the growth of agricultural carbon emissions (Table 6). In other words, with the continuous expansion of the scale of agricultural economy, the total carbon emission from sources, such as agricultural material consumption, increases. However, there is a significant positive correlation between agricultural financial expenditure and agricultural economic growth. This entails that when the government reduces agricultural financial expenditure, the increase of subsidy factor will inhibit agricultural economic growth, and thus, reduce carbon emissions. The efficiency factor is the second most important parameter to restrain agricultural carbon emissions. The efficiency factor is a contrary index variable, i.e., the larger the index, the lower the agricultural production efficiency, and the corresponding agricultural carbon emissions grow. By optimizing agricultural industrial structure and improving agricultural production technology, energy consumption can be reduced and agricultural production efficiency can be improved, which plays a positive role in restraining agricultural carbon emissions. The structure and policy factors contribute to agricultural carbon emissions in most of the provinces and cities, while the foreign trade factor has both promoting and inhibiting effects.

In the northwest region, the driving factors of agricultural carbon emissions have the same effect on Xinjiang and Gansu (Table 5); the foreign trade factor has the greatest impact, which has cut the cumulative agricultural carbon emissions of Xinjiang and Gansu by 12.187914 and 5.481819 million tons respectively,

Table 6. Total effect of each driving factor on 18 provinces and cities.

\begin{tabular}{|c|c|c|c|c|c|c|}
\hline Region/Factor & $\begin{array}{l}\text { Efficiency } \\
\text { factor }\end{array}$ & $\begin{array}{l}\text { Structure } \\
\text { factor }\end{array}$ & $\begin{array}{l}\text { Economic } \\
\text { factor }\end{array}$ & $\begin{array}{l}\text { Subsidy } \\
\text { factor }\end{array}$ & Policy factor & Foreign trade factor \\
\hline Xinjiang & $\downarrow$ & $\downarrow$ & $\uparrow$ & $\downarrow$ & $\uparrow \uparrow$ & $\downarrow \downarrow$ \\
\hline Shaanxi & $\downarrow$ & $\uparrow$ & $\uparrow \uparrow$ & $\downarrow \downarrow$ & $\uparrow$ & $\uparrow$ \\
\hline Gansu & $\downarrow$ & $\downarrow$ & $\uparrow$ & $\downarrow$ & $\uparrow \uparrow$ & $\downarrow \downarrow$ \\
\hline Ningxia & $\downarrow$ & $\uparrow$ & $\uparrow \uparrow$ & $\downarrow \downarrow$ & $\downarrow$ & $\uparrow$ \\
\hline Qinghai & $\downarrow$ & $\uparrow$ & $\uparrow \uparrow$ & $\downarrow \downarrow$ & - & - \\
\hline Inner Mongolia & $\downarrow$ & $\uparrow$ & $\uparrow$ & $\downarrow \downarrow$ & $\downarrow$ & $\uparrow \uparrow$ \\
\hline Heilongjiang & $\downarrow$ & $\uparrow$ & $\uparrow$ & $\downarrow \downarrow$ & $\downarrow$ & $\uparrow \uparrow$ \\
\hline Jilin & $\uparrow$ & $\downarrow$ & $\uparrow \uparrow$ & $\downarrow \downarrow$ & - & - \\
\hline 'Liaoning & $\downarrow$ & $\uparrow$ & $\uparrow$ & $\downarrow$ & $\uparrow \uparrow$ & $\downarrow \downarrow$ \\
\hline Guangxi & $\downarrow$ & $\uparrow$ & $\uparrow$ & $\downarrow \downarrow$ & $\uparrow \uparrow$ & $\downarrow$ \\
\hline Yunnan & $\downarrow$ & $\downarrow$ & $\uparrow$ & $\downarrow \downarrow$ & $\uparrow \uparrow$ & $\uparrow$ \\
\hline Tibet & $\downarrow$ & $\downarrow$ & $\uparrow \uparrow$ & $\downarrow \downarrow$ & - & - \\
\hline Shanghai & $\downarrow$ & $\uparrow$ & $\uparrow$ & $\downarrow \downarrow$ & $\uparrow \uparrow$ & $\downarrow$ \\
\hline Fujian & $\downarrow$ & $\downarrow$ & $\uparrow \uparrow$ & $\downarrow \downarrow$ & - & - \\
\hline Guangdong & $\downarrow$ & $\uparrow$ & $\uparrow$ & $\downarrow \downarrow$ & $\uparrow \uparrow$ & $\downarrow$ \\
\hline Zhejiang & $\downarrow$ & $\uparrow$ & $\uparrow \uparrow$ & $\downarrow \downarrow$ & $\uparrow$ & $\uparrow$ \\
\hline Hainan & $\downarrow$ & $\uparrow$ & $\uparrow$ & $\downarrow$ & $\uparrow \uparrow$ & $\downarrow \downarrow$ \\
\hline Chongqing & $\downarrow$ & $\uparrow$ & $\uparrow$ & $\downarrow \downarrow$ & $\uparrow \uparrow$ & $\downarrow$ \\
\hline
\end{tabular}

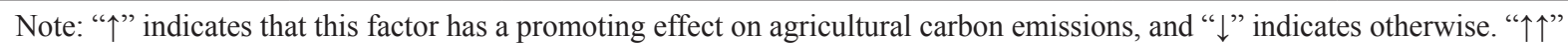
represents the strongest promoting effect, whereas “ $\downarrow \downarrow$ ” represents the strongest inhibiting effect, and "_." represents the uncertainty caused by the lack of data. 
while the factors that promote agricultural carbon emissions include the economic and policy factors. Developing agricultural economic benefits is the main driving factor for the growth of agricultural carbon emissions in Shaanxi, Ningxia, and Qinghai. As agricultural economic development will inevitably lead to an increase in energy consumption and agricultural material input, carbon emissions will certainly increase. This necessitates the need to reduce the carbon emission per unit of agricultural gross domestic product (GDP) rather than the total agricultural carbon emissions through various measures. Therefore, decreasing agricultural carbon emission intensity is the core of the low-carbon economy in Shaanxi, Ningxia, and Qinghai. The subsidy factor plays a major role in curbing carbon emissions. In Inner Mongolia, the subsidy factor cumulatively cut 5.150436 million tons of carbon emissions. As a basic industry for the economic development of the northwest region, agriculture had a total output value of 1165.88 billion yuan in 2017, accounting for $18.68 \%$ of the region's GDP. However, through natural resources, ecological environment, and other restrictions, agricultural development has encountered greater resistance. For example, in 2017, the grain sown area of the six provinces in the northwest region was $15748.5 \mathrm{khm}^{2}$, accounting for $13.35 \%$ of the total sown area of the country. In that year, the grain output was only 75.119 million tons, accounting for $11.35 \%$ of the total national output.

In the northeast region, the influence of each driving factor differs. The foreign trade factor has the strongest promoting effect on agricultural carbon emissions in Heilongjiang, while it has the strongest restraining effect in Liaoning. With the implementation of the Belt and Road development strategy, as well as the development of trade liberalization and regional economic integration, foreign direct investment has become an important factor in the economic development of various countries or regions in the world today. As for the three provinces in the northeast region, Liaoning is relatively advanced in economic and foreign trade development, with a higher degree of openness, because it is the only coastal and border province in the northeast region, and it has the most important comprehensive foreign trade port in the northeast region-Dalian Port. Foreign direct investment can effectively assuage the shortage of agricultural investment, improve the level of agricultural science and technology, promote agricultural modernization, and improve the efficiency of agricultural production. Therefore, the foreign trade factor has a restraining effect on carbon emissions in Liaoning. Conversely, the policy factor plays an important role in promoting agricultural carbon emissions in Liaoning. It has led to a cumulative increase of 6.345058 million tons of carbon emissions, which is 20.4 times the cumulative growth of carbon emissions influenced by six factors. It is shown from Table 5 that the carbon emission increment caused by six influencing factors in the
Heilongjiang province during the study period was the largest, with a cumulative increase of 1.3836 million tons. The utilization of foreign direct investment in Heilongjiang has greatly enhanced the development of the agricultural economy, although there some problems remain in the scale, structure, policy environment, and risk prevention mechanism in the agricultural utilization of foreign investment. Located between the Heilongjiang and Liaoning provinces, Jilin also lags behind in economic development, and the economic factor is the main parameter promoting the growth of agricultural carbon emissions therein.

The situation is similar in the southwest and southeast regions, wherein the subsidy and efficiency factors both play a role in curbing agricultural carbon emissions, but the role of former is more pronounced. The economic factor contributes to agricultural carbon emissions in the southwest and southeast regions in varying degrees, and the policy factor has the strongest promoting effect. The structure and foreign trade factors have both promoting and inhibiting effects on agricultural carbon emissions. The policy factor reflects the degree of government support to agricultural finance. Notably, the greater the financial support for agriculture, the stronger the promotion effect of agricultural carbon emissions, which proves that the relationship between local agricultural carbon emissions and agricultural economic growth has not reached the ideal decoupling state. Guangxi and Guangdong are the provinces with the highest agricultural carbon emissions in the southwest and southeast regions, respectively, and are also among the top three provinces in the Belt and Road region in terms of total carbon emissions. Furthermore, the driving factors of agricultural carbon emissions have the same effect on Guangxi and Guangdong. In Guangxi, the policy factor cumulatively achieved a 13.6135 million tons carbon emission increment, while the subsidy factor cumulatively cut 7.1462 million tons of carbon emissions. In Guangdong, the policy factor cumulatively increased carbon emissions by 7.0198 million tons, whereas the subsidy factor cumulatively cut 5.0455 million tons of carbon emissions. The southwest region is rich in natural resources and densely populated, and it has been maximizing its land use, although the reserve land resources of the cultivated land are insufficient, with more people and less land. Compared with the southwest region, the southeast has more advantages in its level of agricultural management, industrial structure optimization, and foreign trade development.

\section{Conclusions}

\section{Conclusions from the Analysis}

Based on the agricultural data of 18 provinces and cities in the Belt and Road region of China, this study calculated the carbon emissions generated 
by six agricultural land use carbon sources from 2003-2018, and analyzed the spatial and temporal variation characteristics. Thereafter, the LMDI model was used to analyze the driving factors of agricultural carbon emissions. The main conclusions are as follows:

(1) The total agricultural carbon emissions of the provinces and cities in the Belt and Road region of China reached a peak of 26.6326 million tons in 2016 , which indicates an increase of $54.53 \%$ from the 17.2342 million tons in 2003, representing an average annual increase of $3.40 \%$. It showed a downward trend in 2017 and dropped by approximately $4 \%$ to 25.5685 million tons in 2018. Carbon emissions from agriculture grew fastest in 2003-2004 and slowest in 2015-2016. After the "Belt and Road" initiative was proposed, the growth rate of agricultural carbon emissions showed a gradual decline from 2013-2016. This indicates that China is actively fulfilling its obligations and honoring its commitments made abroad, and has made good progress and achieved commendable results.

(2) In terms of provinces, the top three were Heilongjiang, Guangxi, and Guangdong, accounting for $30.45 \%$ of the total agricultural carbon emissions. The bottom three provinces were Tibet, Qinghai, and Shanghai, accounting for only $1.22 \%$ of the total agricultural carbon emissions. Among them, the total annual carbon emissions of the Heilongjiang province (the first) is 41.07 times that of Tibet (the last), indicating that the total agricultural carbon emissions of different provinces and cities in the Belt and Road region vary greatly, while exhibiting the characteristics of "northwest > northeast > southwest > southeast."

(3) Generally, the economic factor promoted agricultural carbon emissions in all provinces and cities in the Belt and Road region of China, while the structure and policy factors promoted agricultural carbon emissions in most provinces and cities. The subsidy factor had a complete inhibitory effect on agricultural carbon emissions in 18 provinces and cities, and the efficiency factor was the second most prominent factor inhibiting agricultural carbon emissions. However, the foreign trade factor had both promoting and inhibiting effects.

(4) In the northwest region, the economic factor played a major role in promoting agricultural carbon emissions, while the subsidy factor had the strongest inhibitory effect. The influence of each driving factor on the three northeast provinces differed. The situation is similar in the southwest and southeast regions, wherein the subsidy and policy factors had a greater impact on agricultural carbon emissions.

\section{Policy Recommendations}

With the promotion of the "Belt and Road" initiative, the position and role of the agricultural market will become more prominent, while problems, such as large agricultural GHG emissions, inadequate utilization of agricultural resources, and large differences in regional agricultural development, still exist. The realization of a coordinated development of grain production and regional agricultural economy, while realizing the low-carbon and green utilization of agricultural land resources in the Belt and Road region poses a key issue for the Chinese government in the future. Thus, we propose the following policy recommendations:

(1) The massive application of chemical fertilizers has increased the supply of agricultural products. To reduce the increased agricultural carbon emissions caused by the use of fertilizers, the following measures can be taken: Using organic rather than chemical fertilizers, as well as slow-release fertilizers instead of the quick-acting variant. Furthermore, replacing chemical fertilizers with organic ones not only directly reduces the amount of chemical fertilizer used but also significantly improves quality. Using slow-release instead of quick-acting fertilizers can realize measured dissemination, improve the utilization efficiency of fertilizers, and reduce quick-acting-fertilizer-induced soil pollution.

(2) Agricultural carbon emissions in the Belt and Road region of China are generally higher in the west and lower in the east. The eastern region has the advantages of geographical location, economic development and agricultural technology innovation. Developing modern agriculture and ecological agriculture is the key toward reducing agricultural carbon emissions. Another important approach is to minimize the proportion of traditional agriculture and innovate the way and mode of agricultural land use. The development of agriculture in the northwest region largely depends on the high-intensity development and utilization of agricultural land, especially the excessive investment on fertilizers and pesticides. Therefore, improving the efficiency of agricultural production will be effective. The western region should pay attention to the cultivation and introduction of research and development personnel.

(3) The government should further increase financial and policy support; farmers should be encouraged to adopt new technologies, while training and education should be available to them. On the premise of ensuring food security, the government should constantly adjust and optimize the structure of the agricultural industry, as well as give proper preference to low-carbon industries, such as forestry and fishery.

\section{Acknowledgements}

This study was funded by the Natural Science Foundation of Shaanxi Province of China (2019JM-008), Shaanxi Academy of Science Research Funding Project (2019K-06), the National Natural Science Foundation of China (No. 41471038; No. 31200500; No. 31860215), the Program for Excellent Young Academic Backbones funded by Northwest University, Shaanxi Academy of Science Research Funding Project (Y19Z604F12), 
and Opening Foundation of Key Laboratory of Resource Biology and Biotechnology in Western China (Northwest University), Ministry of Education (ZSK2018009), and the public health specialty in the Department of Traditional Chinese Medicine (2017-66, 2018-43, 2019-68).

\section{Conflict of Interest}

The authors declare no conflict of interest.

\section{References}

1. LEAL P.A., MARQUES A.C., FUINHAS J.A. Decoupling economic growth from GHG emissions: Decomposition analysis by sectoral factors for Australia. Econ. Anal. Pol. 62, 12, 2019

2. TURKYILMAZ A., SEVIK H., CETIN M., SALEH E.A.A. Changes in Heavy Metal Accumulation Depending on Traffic Density in Some Landscape Plants. Pol. J. Environ. Stud. 27 (5), 2277, 2018.

3. ARICAK B., CETIN M., ERDEM R., SEVIK H., COMETEN H. The Usability of Scotch Pine (Pinus sylvestris) as a Biomonitor for Traffic-Originated Heavy Metal Concentrations in Turkey. Pol. J. Environ. Stud. 29 (2), 1051, 2020

4. HAO Y., CHEN H., WEI Y.M., LI Y.M. The influence of climate change on $\mathrm{CO}_{2}$ (carbon dioxide) emissions: an empirical estimation based on Chinese provincial panel data. J. Clean Prod. 131, 667, 2016.

5. LIN B.Q., FEI R.L. Regional differences of $\mathrm{CO}_{2}$ emissions performance in China's agricultural sector: A Malmquist index approach. Eur. J. Agron. 70, 33, 2015.

6. LI Q., HAN Y. Decoupling Effect of Agricultural Carbon Emission in Anhui Province and Factors Influencing the Emission. J. Anhui Agric. Univ. 25 (2), 2016 [In Chinese].

7. FANG G.C., LU L.X., TIAN L.X., HE Y., BAI Y. Can China achieve the energy-saving and emission reducing objectives during the "13 $3^{\text {th }}$ Five-Year-Plan"? - A systematic evolutionary analysis. J. Clean Prod. 262, 12, 2020.

8. HUANG X.Q., XU X.C., WANG Q.Q., ZHANG L., GAO X., CHEN L.H. Assessment of Agricultural Carbon Emissions and Their Spatiotemporal Changes in China, 1997-2016. Int. J. Env. Res. Public Health. 16 (17), 2019.

9. YADAV D., WANG J.Y. Modelling carbon dioxide emissions from agricultural soils in Canada. Environ. Pollut. 230, 1040, 2017

10. CETIN M., SEVIK H. Change of air quality in Kastamonu city in terms of particulate matter and $\mathrm{CO}_{2}$ amount. Oxid. Commun. 39 (4), 3394, 2016.

11. ADEWALE C., REGANOLD J.P., HIGGINS S., EVANS R.D., CARPENTER-BOGGS L. Improving carbon footprinting of agricultural systems: Boundaries, tiers, and organic farming. Environ. Impact Assess. Rev. 71, 41, 2018.

12. LU X., KUANG B., LI J., HAN J., ZHANG Z. Dynamic Evolution of Regional Discrepancies in Carbon Emissions from Agricultural Land Utilization: Evidence from Chinese Provincial Data. Sustainability. 10 (2), 2018

13. CHU Y., XIE L., YUAN Z. Composition and spatiotemporal distribution of the agro-ecosystem carbon footprint: A case study in Hebei Province, north China. J. Clean Prod. 190, 838, 2018.

14. CETIN M., SEVIK H., SAAT A. Indoor Air Quality: the Samples of Safranbolu Bulak Mencilis Cave. Fresen. Environ. Bull. 26 (10), 5965, 2017.

15. CHUAI X.W., FENG J.X. High resolution carbon emissions simulation and spatial heterogeneity analysis based on big data in Nanjing City, China. Sci. Total Environ. 686, 828, 2019.

16. SUMABAT A.K., LOPEZ N.S., YU K.D., HAO H., LI R., GENG Y., CHIU A.S.F. Decomposition analysis of Philippine $\mathrm{CO}_{2}$ emissions from fuel combustion and electricity generation. Appl. Energ. 164, 795, 2016.

17. CETIN M. A Change in the Amount of $\mathrm{CO}_{2}$ at the Center of the Examination Halls: Case Study of Turkey. Stud. Ethno-Med. 10 (2), 146, 2016

18. AKRAM Z., ENGO J., AKRAM U., ZAFAR M.W. Identification and analysis of driving factors of $\mathrm{CO}_{2}$ emissions from economic growth in Pakistan. Environ. Sci. Pollut. R. 26 (19), 19481, 2019.

19. XU B., LIN B. Factors affecting $\mathrm{CO}_{2}$ emissions in China's agriculture sector: Evidence from geographically weighted regression model. Energy Policy. 104, 404, 2017.

20. CUI H.R., ZHAO T., SHI H.J. STIRPAT-Based Driving Factor Decomposition Analysis of Agricultural Carbon Emissions in Hebei, China. Pol. J. Environ. Stud. 27 (4), 1449, 2018.

21. XIONG C., YANG D., HUO J. Spatial-Temporal Characteristics and LMDI-Based Impact Factor Decomposition of Agricultural Carbon Emissions in Hotan Prefecture, China. Sustainability. 8 (3), 2016.

22. SU M., JIANG R., LI R. Investigating Low-Carbon Agriculture: Case Study of China's Henan Province. Sustainability. 9 (12), 2017.

23. ZHANG P., HE J., HONG X., ZHANG W., QIN C., PANG B., LI Y., LIU Y. Regional-Level Carbon Emissions Modelling and Scenario Analysis: A STIRPAT Case Study in Henan Province, China. Sustainability. 9 (12), 2017.

24. CETIN M., SEVIK H. Measuring the Impact of Selected Plants on Indoor $\mathrm{CO}_{2}$ Concentrations. Pol. J. Environ. Stud. 25 (3), 973, 2016.

25. ISMAEL M., SROUJI F., BOUTABBA M.A. Agricultural technologies and carbon emissions: evidence from Jordanian economy. Environ. Sci. Pollut. R. 25 (11), 10867, 2018.

26. ENGO J. Decomposing the decoupling of $\mathrm{CO}_{2}$ emissions from economic growth in Cameroon. Environ. Sci. Pollut. R. 25 (35), 35451, 2018.

27. SARAVIA-MATUS S.L., HORMANN P.A., BERDEGUE J.A. Environmental efficiency in the agricultural sector of Latin America and the Caribbean 1990-2015: Are greenhouse gas emissions reducing while agricultural production is increasing? Ecol. Indic. 102, 338, 2019.

28. XIONG C.H., YANG D.G., HUO J.W., ZHAO Y.N. The Relationship between Agricultural Carbon Emissions and Agricultural Economic Growth and Policy Recommendations of a Low-carbon Agriculture Economy. Pol. J. Environ. Stud. 25 (5), 2187, 2016.

29. ZHANG H., GUO S.D., QIAN Y.B., LIU Y., LU C.P. Dynamic analysis of agricultural carbon emissions efficiency in Chinese provinces along the Belt and Road. Plos One. 15 (2), 22, 2020.

30. ZHI J., GAO J. Analysis of carbon emission caused by food consumption in urban and rural inhabitants in China. Prog. Geogr. 28, 429, 2009 [In Chinese]. 
31. TIAN Y., ZHANG J.B., HE Y.Y. Research on SpatialTemporal Characteristics and Driving Factor of Agricultural Carbon Emissions in China. J. Integr. Agr. 13 (6), 1393, 2014.

32. WU F., LI L., ZHANG H., CHEN F. Effects of conservation tillage on net carbon flux from farmland ecosystems. Chin. J. Ecol. 26, 2035, 2007 [In Chinese].

33. WEST T.O., MARLAND G. A synthesis of carbon sequestration, carbon emissions, and net carbon flux in agriculture: comparing tillage practices in the United States. Agr. Ecosyst. Environ. 91 (1), 217, 2002.

34. ANG B.W. Decomposition analysis for policymaking in energy. Energy Policy. 32 (9), 1131, 2004.

35. ANG B.W. The LMDI approach to decomposition analysis: a practical guide. Energy Policy. 33 (7), 867, 2005.

36. ANG B.W., LIU F.L. A new energy decomposition method: perfect in decomposition and consistent in aggregation. Energy. 26 (6), 537, 2001. 